\title{
Análisis del dictamen constitucional sobre el error inexcusable en ecuador
} Analysis of the constitutional opinion on the inexcusable error in Ecuador

\author{
Orlando Iván Ronquillo-Riera \\ uq.orlandoronquillo@uniandes.edu.ec \\ Universidad Regional Autónoma de los Andes, Quevedo \\ Ecuador \\ https://orcid.org/0000-0001-6020-7255 \\ Michael Alexander Cano-Paredes \\ dq.michaelacp24@uniandes.edu.ec \\ Universidad Regional Autónoma de los Andes, Quevedo \\ Ecuador \\ https://orcid.org/0000-0002-4431-5077 \\ Adriana Doménica Macías-Díaz \\ dq.adrianadmd39@uniandes.edu.ec \\ Universidad Regional Autónoma de los Andes, Quevedo \\ Ecuador \\ https://orcid.org/0000-0003-0563-139X \\ Geovanna Michelle Najera-Tello \\ dq.geovannamnt38@uniandes.edu.ec \\ Universidad Regional Autónoma de los Andes, Quevedo \\ Ecuador \\ https://orcid.org/0000-0001-7487-7938
}

Recepción: 15 de septiembre 2021

Revisado: 25 octubre 2021

Aprobación: 15 de noviembre 2021

Publicación: 01 de diciembre 2021 


\section{Estimado Editor (a):}

La Corte constitucional procede a dictar sentencia en el caso No. 3-19-CN (error inexcusable), de acuerdo con los antecedentes procesales sobre el Pleno del Consejo de la Judicatura cuando resolvió acoger parcialmente el informe motivado suscrito por la Directora Provincial de Esmeraldas del Consejo de la Judicatura, el cual dejó bajo la destitución al doctor César Ernesto Hernández Pazmiño, juez primero adjunto de la Familia, Mujer, Niñez y Adolescencia de Esmeraldas, declarándolo culpable (responsable) de lo expuesto en el Código Orgánico de la Función Judicial sobre Error Inexcusable. Cabe recalcar que la Corte Constitucional es el único órgano de interpretación en materia constitucional, para esto se emiten las siguientes nociones preliminares y que se tomó en consideración para la siguiente decisión.

En este sentido, los problemas que la Corte Constitucional encontró dentro de este análisis se llevaron a cabo sobre la independencia judicial y responsabilidad en el marco Constitucional, La tipificación del dolo, la manifiesta negligencia y el error inexcusable en relación con la Constitución, especialmente el principio de legalidad y la seguridad jurídica, Las competencias constitucionales del Consejo de la Judicatura en relación con estas faltas disciplinarias y el procedimiento conforme a la Constitución, y la Respuesta de la Corte al caso concreto objeto de consulta. Según Páez (2013) Ecuador ha estado inmerso en una estructura de poder que ha determinado que la justicia sea parte de un juego político. (p.115)

Sin embargo, el mecanismo del error inexcusable dentro de una normativa interna se encuentra establecida en el código orgánico de la Función Judicial, dentro de las faltas consideradas como "gravísimas" pero el inconveniente se da ya que el legislador no ha determinado cuando y que supuestos se califica como tal, es decir que no se ha definido su significado ni tampoco cuales son los elementos o componentes que han de concurrir para que se configure esta falta, lo que causa es un vacío legal dentro de la norma ya mencionada.

Al respecto, Zapata Fajardo et al, (2021) expone: 
La figura del error inexcusable, ha traído consecuencias catastróficas para los operadores de justicia, pues ha significado una camisa de fuerza en el deber de administrar justicia. Mediante esta figura, se han destituido a muchos jueces, pues el Consejo de la Judicatura, desbordando sus competencias ha ejercido control jurisdiccional al revisar fallos emitidos por jueces, situación sin lugar a dudas inconstitucional, pues únicamente se puede efectuar este control, por el juez superior en apelación o dentro de cualquier otro recurso, de conformidad con el principio de doble conforme, establecido en el artículo 76, numeral 7, literal m de la Constitución. (p.37)

La figura del error inexcusable antes del dictamen de constitucionalidad por parte de la Cote Constitucional, vulneraba el principio de independencia interna que goza la función Judicial; en virtud que un órgano administrativo como lo es el Consejo de la Judicatura no podía efectuar control jurisdiccional sobre decisiones netamente jurisdiccionales, pues para esto están los recursos judiciales.

Por otro lado, Salgado Ledesma (2012) indican que:

En una tendencia que tiende a universalizar el contenido y la protección de los derechos humanos, las decisiones de la Corte Interamericana y de otros tribunales como la Corte Europea de Derechos Humanos suelen sobreponerse a las decisiones soberanas expresadas por cualquier Estado al suscribir una obligación internacional cuando se trata de lograr su eficacia (p.225)

En tal sentido, el error inexcusable fue utilizado como una herramienta de presión política dentro del sistema de administración de justicia, que convirtió al Consejo de la Judicatura en un órgano ejecutor del gobierno de turno, más que en una entidad encargada de administrar el sistema Judicial. La única manera de garantizar la justicia como un derecho humano, es respetando la separación de poderes y la independencia interna y externa que deben tener los jueces en sus actuaciones. Por su parte, la Organización de las Naciones Unidas refiriéndose dentro de los Principios básicos relativos a la independencia de la judicatura en 1985, estableció que "La independencia de la judicatura será garantizada por el Estado y proclamada por la Constitución o la legislación del país".

\section{FINANCIAMIENTO}

No monetario. 


\section{AGRADECIMIENTO}

A la Universidad Regional Autónoma de los Andes, Quevedo, por motivar el desarrollo de la Investigación.

\section{REFERENCIAS CONSULTADAS}

Asamblea Nacional Constituyente de la República del Ecuador, (2008). Constitución de la República del Ecuador. [Constitution of the Republic of Ecuador]. Montecristi. Registro Oficial 449 de 20-oct-2008. Recuperado de https://n9.cl/sia

Asamblea Nacional del Ecuador. (2011). Código Orgánico de la Función Judicial. [Organic Code of the Judicial Function]. Quito: Registro Oficial Suplemento 544. Recuperado de: https://n9.cl/wm40

Corte Constitucional del Ecuador, Sentencia № 3-19 CN/20 Caso № 3-19-CN (Error Inexcusable) (Corte Constitucional del Ecuador. [Constitutional Court of Ecuador] Recuperado de: https://n9.cl/97a4

Organización de las Naciones Unidas. (1985). Declaración sobre los Principios Fundamentales de Justicia para las Víctimas de Delitos y del Abuso de Poder. [Statement on the Fundamental Principles of Justice for Victims of Crime and Abuse of Power] Recuperado de: https://n9.cl/pv9vx

Páez, A. (2013). La metida de mano en la justicia. [The hand in the hands of justice]. Quito: Paradiso.

Salgado Ledesma, E. (2012). La probable inejecución de las sentencias de la Corte Interamericana de Derechos Humanos. [ The probable non-execution of the judgments of the Inter-American Court of Human Rights]. Cuestiones constitucionales, (26), 221-260. Recuperado de: https://n9.cl/7xxnh

Zapata Fajardo, M.; Ronquillo Riera, O.; y Atención González, R. (2021) La Corte Constitucional como garante del Principio de Independencia Judicial en Ecuador. [The Constitutional Court as guarantor of the Principle of Judicial Independence in Ecuador]. Iustitia Socialis. 6(10), 33-46. http://dx.doi.org/10.35381/racji.v6i10.1150 
FUNDACIÓN KOINONIA (F.K). Santa Ana de Coro, Venezuela

Orlando Iván Ronquillo-Riera; Michael Alexander Cano-Paredes; Adriana Doménica Macías-Díaz; Geovanna Michelle Najera-Tello

@2021 por los autores. Este artículo es de acceso abierto y distribuido según los términos y condiciones de la licencia Creative Commons Atribución-NoComercial-Compartirlgual 4.0 Internacional (CC BY-NC-SA 4.0) (https://creativecommons.org/licenses/by-nc-sa/4.0/). 